\title{
Surface Modification of Dental Implants - A Review
}

\author{
Shamaa Anjum ${ }^{1}$, Arvina Rajasekar ${ }^{2}$ \\ 1, 2 Department of Periodontics, Saveetha Dental College and Hospitals, Saveetha Institute of \\ Medical and Technical Sciences, Saveetha University, Chennai, Tamil Nadu, India.
}

\section{ABSTRACT}

The use of dental implants for the replacement of missing teeth has increased in the last 30 years. The success rates for implant placement depend on a series of both biological and clinical steps which starts with primary stability that is being provided by the amount, quality and the distribution of bone within the proposed implant site. The most important factor in implant osseointegration is surface roughness, which shows increased osteoblast activity at 1 to $100 \mu \mathrm{m}$ of the surface roughness when compared to a smooth surface. Rough surfaces have excellent osseointegration than smooth surfaces, but the results of research have been diverse, and it is evident that multiple treatments provide good results. The surfaces of a dental implant have been modified in several ways to improve its biocompatibility and speed up osseointegration. Literature says that any surface modification provides a good surface for osseointegration of the implant when the surface roughness is about 0.44 $\sim 8.68 \mu \mathrm{m}$. It is also said that acid etching and coating are the most preferred methods for creating good roughness of the implant surface. From animal studies, it is known that implant surface modifications provided by biomolecular coating seemed to enhance the osseointegration by promoting peri-implant bone formation in the early stages of healing. It also seemed to improve histomorphometric analysis and biomechanical testing results. This article reviews the surface modifications of dental implants for the achievement of better success rates. Various methods are used to modify the topography or the chemistry of the implant surfaces which includes acid etching, anodic oxidation, blasting, treatment with fluoride, and calcium phosphate coating. These modifications provide a faster and a stronger osseointegration. ${ }^{1}$ Recently, hydrophilic properties added to the roughened surfaces or some osteogenic peptides coated on the surfaces shows higher biocompatibility and have induced faster osseointegration compared to the existing modified surfaces. With development in surface engineering techniques, new information on the properties, behaviour, and the reaction of various materials could be discovered which in turn allows the discovery of new materials, modification techniques and design of bio implants for the future.

\section{KEY WORDS}

Dental Implants, Surface Modifications, Biocompatibility, Surface Topography
Corresponding Author: Dr. Arvina Rajasekar, Senior Lecturer, Department of Periodontics, Saveetha Dental College and Hospitals, Saveetha Institute of Medical and Technical Sciences, Saveetha University,

Chennai - 600077, Tamil Nadu, India.

E-mail:drarvina92@gmail.com

DOI: $10.14260 / j e m d s / 2021 / 265$

How to Cite This Article:

Anjum S, Rajasekar A. Surface modification of dental implants - a review. J Evolution Med Dent Sci 2021;10(17):1246-1250, DOI: $10.14260 /$ jemds/2021/265

Submission 08-09-2020,

Peer Review 24-02-2021,

Acceptance 02-03-2021,

Published 26-04-2021.

Copyright (C) 2021 Shamaa Anjum et al. This is an open access article distributed under Creative Commons Attribution License [Attribution 4.0 International (CC BY 4.0)] 


\section{BACKGROUND}

Use of implants for oral and maxillofacial region continues to grow. Implants are used for several purposes which include, replacement of missing teeth, rebuilding craniofacial skeleton, providing anchorage for orthodontic treatments and helping in the formation of bone in the process of osteogenesis. More than 220 brands of implants produced by 80 manufacturers have been known. With the various materials, the surface modification, shapes, lengths, and widths of the implants that are available, clinicians are able to choose from more than 2000 implants. This variety of options is good but it might complicate the selection of the correct implant based on sound evidence. The usage of metallic biomaterials for biomedical implants has been traced back from the 19th century. ${ }^{2}$ In recent years, manufacturing and fabrication features of implants are of primary concern in biomaterial engineering. ${ }^{3}$ The selection of implants relies mainly on the proposed application. ${ }^{4}$ Despite the wide variety of metals and alloys that are available in the materials industry, only a few metals and alloys fit the requirements for development as bio implants. The commonly used metallic biomaterials are 316L stainless steel (316L SS), ${ }^{5}$ cobalt-based (Co-Cr) alloys, ${ }^{6}$ titanium and its alloys. ${ }^{7}$ Apart from these metals, $\mathrm{NiTi},{ }^{8}$ magnesium $(\mathrm{Mg})^{9}$ and tantalum (Ta) ${ }^{10}$ which are known as the "miscellaneous material" implants are also becoming a potential candidate for developing into bioimplants.

Endosseous dental implants have created tremendous changes in the approach of dental care for patients with missing teeth. The success rates for implant occurs through a series of both clinical and biological steps which starts with stability that is provided by the amount, quality and distribution of bone. ${ }^{11}$ After the implant placement a series of bone remodelling steps take place. Bone adaptation of an implant starts with the bone turnover at the interface. The clinical end point of this process is measured by the lack of signs and symptoms of aggressive chronic inflammation and an assessment of bone adapted to the interface of the dental implant which is determined radiographically. The long-term success rate of an implant depends on the enhanced osseous stability. In recent years, transmucosal dental implant or implant abutment interfaces has gained popularity. The mechanical and biological stability plays a major role in maintaining a sufficient volume of connective tissue with minimal inflammatory infiltrate and it is provided by design and the surfaces in the connective tissue and junctional epithelial environment. In order to increase the success rates of implant therapy, significant researches have been done on implant biomaterials. ${ }^{12}$ The technologies has now evolved from a simple modification of the oxide surface to nano-scale modifications which forms a uniform and consistent surface. There are developing technologies to utilise the changes in surface chemistry to assist in the stability of osseous and transmucosal environment. ${ }^{13}$ This review discusses the surface modification of these implants.

\section{THE TISSUE IMPLANT INTERFACE}

The goal of research in the field of implantology is to design the implants that bring about controlled and rapid integration into the surrounding tissues. ${ }^{14}$ Events that leads to the stability of an implant takes place mainly at the tissue-implant interface. Formation of the tissue-implant interface is complex process and requires a number of factors which includes the implant-related factors, such as materials, shapes, topography, and surface chemistry and the mechanical loading, surgical technique. Patient factors such as the quantity and quality of bone also matters. Dental implants must also interact with the epithelium and submucosal soft connective tissues in contrast to the orthopaedic prostheses, which are designed to interact with only the bone.

Following implant placement, events take place on the biological side as well as on the materials side. On the implant side, electrochemical events take place and cause the oxide layer to double or triple in its thickness. The electrochemical reactions cause biological ions such as calcium, phosphorus, and sulphur to get incorporated and there is release metal ions. Information about the metals released from dental implants are less when compared to other implant devices. On the biological side, water molecules and hydrated ions react with implant surface within nanoseconds. 15 The presence of the substrate alters the organisation of water molecules. Hundreds of biomolecules from our body fluids interacts with the surface of the implant. A complex and a cascade of events takes place; during which smaller molecules replace high affinity molecules. There may be alteration in the orientation and conformation of these biomolecules due to their interaction with implant surface. With time, the cells will encounter an implant surface that should have been preconditioned with biomolecules. Formation of a peri implant soft tissue barrier is important for protection of the bone-implant interface from microbiological changes. Lack of a peri mucosal seal can cause apical migration of the epithelium and encapsulation of the root of the implant. The peri-implant mucosa forms a cuff-like barrier and adheres to the implant. 16

\section{IMPORTANT SURFACE CHARACTERISTICS OF IMPLANTS}

Two surface characteristics are commonly cited as an important determinant for tissue responses. ${ }^{17}$ One which is the topographic or the morphological features of the implant while the other is the chemical properties. Independent studies of the topographic and chemical properties are confounded as the methods used to alter the surface morphology mostly leads to changes in surface chemistry. ${ }^{18}$ In the newer methods for altering the surface characteristics, great attention has been focused on the changes in surface roughness and chemistry. ${ }^{19}$

The surface topography describes surface of implants as "rough" or "smooth". Terms like contact guidance and rugophilia have been used to describe the interaction between the tissue and textured implant surfaces. ${ }^{20}$ Contact guidance is directional guidance provided by a substrate and rugophilia means "rough-loving". ${ }^{21}$ Porous materials are examples of surface roughness and they allow growth of tissues into implants and enhance its integration. ${ }^{22}$ Researches on bioactive materials show that bone may grow into smaller pores and that the size and volume density of these 
interconnections are critical considerations for proper blood circulation and extracellular liquid exchange.

The surface energy, charge and composition are physicochemical properties that can be manipulated to improve the interaction of implants with the surrounding cells and tissues of the site of implant placement. ${ }^{23}$ Glow discharge treatment process is one which causes the materials to be exposed to ionized inert gas like argon. ${ }^{24}$ During collisions with the substrate, high-energy species, "scrub" contaminants from the surface, thereby non saturating the surface bonds and increase the surface energy. ${ }^{25}$ The higher surface energy will cause the adsorption of biomolecules, which in turn affects subsequent cell and tissue behaviour. ${ }^{26}$

\section{MACRO RETENTIVE FEATURES OF AN IMPLANT}

Dental implants have one of the three important types of macro-retentive features: screw thread design (tapped or selftapping), solid body press-fit designs and / or sintered bead technologies. These features enhance the initial implant stability and create a volumetric space for growth of bone into the implant. A notable biological property of bone is that it responds favourably to compressive forces but not to shear forces. The screw thread implants have been designed to achieve a compressive loading of the surrounding cortical or cancellous bone and the thread designs focuses on reducing the surrounding shear forces by reducing height of the thread profile and increasing the number of threads per unit area. This increases the strength of the implant body by increasing the amount of remaining wall thickness of the implant body. ${ }^{27}$ The application of sintering technology to create a meshwork or sintered beads as a surface for bone to grow into, may increase the success rates of short implants which are less that $10 \mathrm{~mm}$ in length. This is applied to only dental implant systems with very short implants lengths. ${ }^{28}$

\section{MICRO RETENTIVE FEATURES OF AN IMPLANT}

When an implant is placed there is a cascade of cellular processes that causes growth and differentiation of new bone along the surface of the biomaterial. Following the placement of the implant, the bone surrounding the implant undergoes necrosis, resorption and replacement. A mature haversian bone replaces woven like cell rich bone by remodelling. ${ }^{29}$ The current goal is to provide enhanced osseous stability through micro-surface of the implants. These strategies can enhance the immigration of new bone (i.e., osteoconduction) by changes in the surface topography of the implant (i.e., surface roughness), biological methods that manipulate the type of cells that grow onto the implant surface and strategies to utilise the implant as a vehicle for local delivery of a bioactive coating. ${ }^{30}$ The success rate of an implant is done by increasing the amount of bone that contacts the implant. In the design of a dental implant, it is assumed that greater the surface area, greater is the surface roughness of the implant which enhances the surface area and allows a greater area for load transfer by the bone against the implant. ${ }^{31}$ Micromechanical features of the implant enhances the secondary integration which is bone growth, turnover and remodelling. Acid etching increases the roughness of the grit blasted surface of the implant and creates the potential for a nanometre-scale topography on top of the macroscale roughness thereby allowing bone to adapt to the surface under the elevated shear forces. $^{32}$ The features of an implant design were thought to require diameter of pores to be $100 \mu \mathrm{m}$ or greater for the ingrowth of bone although clinically, surface roughness may actually be much finer as on the nanoscale level.

\section{SURFACE ROUGHNESS BY} ACID ETCHING / BLASTING

Titanium implants acquire surface roughness by either grit blasting and etching or by blasting of the surface alone. A modification of the titanium dioxide grit blasted surface is done by hydrofluoric acid etching to create surface roughness on the blasted surface of the implant. The optimisation criteria requires the maintenance of the macro roughness caused by the blasting process and surface etching of the implant to influence the secondary osseointegration. ${ }^{33}$

Currently there are two main, but interrelated approaches that can be checked to enhance bone adaptation to surface of dental implant. ${ }^{34}$ These involve either the addition of biological mediators such as cell adhesion or bioactive peptides or creating reproducible nanoscale surface features. ${ }^{35}$ Both the approaches improves the adaptation of the implant into the trabecular bone. ${ }^{36}$ The addition of cell adhesion peptides or growth factors to the implant surface aids as a local drug delivery device. ${ }^{37}$ The changes in the fibrin scaffold is key to the future of implant surface technology..$^{38}$ Modifying the titanium oxide surface requires placement of various configurations of peptide sequences which is present in the extracellular matrix proteins. ${ }^{39}$ Manipulating the biological responses creates topographical features at a nanoscale level. Relevant features are at nanometre scale of the range of $1-100 \mathrm{~nm}$ in dimension. Researches state that the conventional Newtonian characteristics of materials are different for a nanomaterial that shows increased number of atoms at the surface and surface area and electron delocalisation. 40 At the nanoscale, molecular interactions implant can be targeted to cause certain cell level response.

\section{SURFACE MODIFICATION TO REDUCE CORROSION}

To be chosen as biomedical implants, the metals used for the implant must be compatible with the human body. ${ }^{41}$ The process of corrosion is the degradation of the material into its constituent atoms due to chemical reactions that happens between the materials and its surroundings. Corrosion causes changes in the unstable metal under the thermodynamic state of the material and electrochemical oxidation of metals in reaction with oxygen. Various metallic implants are known to have great resistance to corrosion which enhances the life of the implant. However, studies show that corrosion slowly takes place once a metal is implanted in the human bodies due 
to electrochemical reactions. The internal environment of our body is tissue fluid which produces reactive interstitial fluid and responds ionically to the biomaterials due to the presence of water, chloride ions, sodium ions, plasma, proteins and amino acid present in the saliva. The metal ions from bioimplants cause not only serious infections and other health issues but also to the statutory authority in the biomedical industry. ${ }^{42}$ It is essential that the material of an implant undergoes a screening test to identify its performance in various environments. ${ }^{4} 3$

There are three types of corrosion that can occur on the metallic surface of an implant: uniform corrosion, pitting corrosion and corrosion that occurs due to electrochemical or mechanical processes. Several techniques of surface modification have been identified to overcome and improve the performance of the implant due to internal corrosive human body surroundings. Several researches have been focused on the improvement of surface engineering tools to make the implants more bio functional and resistant to corrosion for superior mechanical properties. The techniques that are used include the deposition of a uniformly thin coating, development of a stable passivation oxide layer, ion beam processing and surface texturing.

The hydroxyapatite coating on the surface of the implant might start to degrade with time ${ }^{44}$ which affects the behaviour of the metals. Before the development of a coating and surface treatment metals, a stable surface oxide layer on the passivated metal surface should be formed. This oxide layer plays an important role in corrosion resistance and changing the surface oxide layer through the release of metalions. ${ }^{45}$ The surface oxide layer has ability to change its composition due to the responses with the surfaces of living tissues and the metallic materials. The surface oxide layer on metallic implants plays a vital role in the biocompatibility. ${ }^{46}$

Ion beam methods which is one of the surface modification techniques contributes in the alteration of metallic implant surfaces. This ion beam method improves the biocompatibility with wear resistance and corrosion resistance by the formation of an appetite layer such as titanium dioxide (TiO2) and titanium nitride (TiN) film. ${ }^{47}$ Ion implantation processes on the surface of the bio implants reduces the release of the metal ions thereby producing low friction coefficient which hardens the surface of the implant and eventually improve the wear tendency of the implant. ${ }^{48}$ Several studies shows that implantation of oxygen and nitrogen ion show improved surface properties of the implant

In recent years, surface texturing method has been introduced to reduce corrosion, increase the biocompatibility and promote osseointegration of the implant. ${ }^{49}$ Techniques such as acid etching, plasma spraying, electropolishing, anodic oxidation, and bioactive coatings can be used to enhance the interaction between bone and surface implants. ${ }^{50}$ Rough surfaces of implants encourage bone healing and biocompatibility and promotes rapid integration of the implants.

\section{CONCLUSIONS}

The use of implants to replace missing teeth has progressed immensely over the past few years. Recent developments in the area of surface technology aim to enhance the tissue surface interactions furthermore. One of the most desired characteristics of implants is the quick establishment of tissue implant interface and the firm maintenance of the same. Since many variables are associated with the success rates of the dental implants, it becomes difficult to predict the success rates of an implant. Current development in surface engineering techniques aims at gaining information on the properties, behaviour, and the reaction of various materials allowing the discovery of various new materials, modification of existing techniques and design of bio implants for the future.

Financial or other competing interests: All authors received nonfinancial support from Saveetha Institute of Medical and Technical Sciences during the study.

Disclosure forms provided by the authors are available with the full text of this article at jemds.com.

\section{REFERENCES}

[1] Albrektsson T, Becker W, Coli P, et al. Bone loss around oral and orthopedic implants: an immunologically based condition. Clin Implant Dent Relat Res 2019;21(4):78695.

[2] Anselme $K$, Linez $P$, Bigerelle $M$, et al. The relative influence of the topography and chemistry of TiAl6V4 surfaces on osteoblastic cell behaviour. Biomaterials 2000;21(15):1567-77.

[3] Badylak SF. Host response to biomaterials: the impact of host response on biomaterial selection. Academic Press 2015.

[4] Berry DJ, Lieberman J. Surgery of the Hip E-Book. Elsevier Health Sciences 2012.

[5] Brunette DM, Tengvall $\mathrm{P}$, Textor $\mathrm{M}$, et al. Titanium in medicine: material science, surface science, engineering, biological responses and medical applications. Springer Science and Business Media 2012.

[6] Chevalier J, Gremillard L, Deville S. Low-temperature degradation of zirconia and implications for biomedical implants. Annual Review of Materials Research 2007;37(1):1-32.

[7] Choulis NH, Aronson JK. 49 Miscellaneous drugs and materials, medical devices and techniques. Side Effects of Drugs Annual 2007;29:596-617.

[8] Chrcanovic BR, Kisch J, Albrektsson T, et al. Intake of proton pump inhibitors is associated with an increased risk of dental implant failure. Int J Oral Maxillofac Implants 2017;32(5):1097-102.

[9] Curtis RV, Watson TF. Dental biomaterials: imaging, testing and modelling. Elsevier 2014.

[10] Disegi JA, Eschbach L. Stainless steel in bone surgery. Injury 2000;31(Suppl 4):2-6.

[11] Dorozhkin SV. Calcium orthophosphates: applications in nature, biology and medicine. CRC Press 2012.

[12] Drury JL, Mooney DJ. Hydrogels for tissue engineering: scaffold design variables and applications. Biomaterials 2003;24(24):4337-51.

[13] Dukhan N. Metal foams: fundamentals and applications. DEStech Publications 2013.

[14] Eriksson AR. Heat-induced bone tissue injury: an in vivo investigation of heat tolerance of bone tissue and 
temperature rise in the drilling of cortical bone. Laboratory of Experimental Biology 1984.

[15] Galli S, Jimbo R, Naito Y, et al. Chemically modified titanium-zirconium implants in comparison with commercially pure titanium controls stimulate the early molecular pathways of bone healing. Clin Oral Implants Res 2017;28(10):1234-40.

[16] Geng J, Yan W, Xu W, eds. Application of the finite element method in implant dentistry. Springer Science \& Business Media 2008.

[17] Hulbert SF, Morrison SJ, Klawitter JJ. Tissue reaction to three ceramics of porous and non-porous structures. J Biomed Mater Res 1972;6(5):347-74.

[18] Jamesh M, Sankara TS, Chu PK. Thermal oxidation of titanium: evaluation of corrosion resistance as a function of cooling rate. Materials Chemistry and Physics 2013;138(2-3):565-72.

[19] Jokstad A. Osseointegration and dental implants. John Wiley \& Sons 2009.

[20] Kasemo B, Gold J. Implant surfaces and interface processes. Adv Dent Res 1999;13:8-20.

[21] Kieswetter K, Schwartz Z, Dean DD, et al. The role of implant surface characteristics in the healing of bone. Crit Rev Oral Biol Med 1996;7(4):329-45.

[22] Kumar S, Narayan TSNS, Raman SGS, et al. Surface modification of CP-Ti to improve the fretting-corrosion resistance: thermal oxidation vs. anodizing. Materials Science and Engineering: C 2010;30(6):921-7.

[23] Kurtz SM, Devine JN. Peek biomaterials in trauma, orthopedic and spinal implants. Biomaterials 2007;28(32):4845-69.

[24] Li BY, Rong LJ, Li YY, et al. A recent development in producing porous $\mathrm{Ni}-\mathrm{Ti}$ shape memory alloys. Intermetallics 2000;8(8):881-4.

[25] Lin HY, Liu Y, Wismeijer D, et al. Effects of oral implant surface roughness on bacterial biofilm formation and treatment efficacy. Int J Oral Maxillofac Implants 2013;28(5):1226-31.

[26] Lossdörfer S, Schwartz Z, Wang C, et al. Microrough implant surface topographies increase osteogenesis by reducing osteoclast formation and activity. J Biomed Mater Res A 2004;70(3):361-9.

[27] Malet J, Mora F, Bouchard P. Implant dentistry at a glance. John Wiley \& Sons 2011.

[28] Masaki C, Schneider GB, Zaharias R, et al. Effects of implant surface microtopography on osteoblast gene expression. Clin Oral Implants Res 2005;16(6):650-6.

[29] Milošev I, Strehblow HHS. The composition of the surface passive film formed on CoCrMo alloy in simulated physiological solution. Electrochimica Acta 2003;48(19):2767-74.

[30] Mosser DM, Edwards JP. Exploring the full spectrum of macrophage activation. Nat Rev Immunol 2008;8(12):958-69.

[31] Müller KH, Kulkarni J, Motskin M, et al. pH-dependent toxicity of high aspect ratio $\mathrm{ZnO}$ nanowires in macrophages due to intracellular dissolution. ACS Nano 2010;4(11):6767-79.

[32] Murty BS, Shankar P, Raj B, et al. Textbook of nanoscience and nanotechnology. Springer Science \& Business Media 2013.

[33] Park JB. Biomaterials science and engineering. Springer Science \& Business Media 2012.

[34] Popat KC, Swan EEL, Mukhatyar V, et al. Influence of nanoporous alumina membranes on long-term osteoblast response. Biomaterials 2005;26(22):4516-22.

[35] von Recum AF. Handbook of biomaterials evaluation: scientific, technical and clinical testing of implant materials. $2^{\text {nd }}$ edn. CRC Press 1998.

[36] Sánchez AR, Sheridan PJ, Kupp LI. Is platelet-rich plasma the perfect enhancement factor? A current review. Int J Oral Maxillofac Implants 2003;18(1):93-103.

[37] Narayanan TSNS, Park IS, Lee MH. Surface modification of magnesium and its alloys for biomedical applications: biological interactions, mechanical properties and testing. $1^{\text {st }}$ edn. Elsevier 2015.

[38] Shadanbaz S, Dias GJ. Calcium phosphate coatings on magnesium alloys for biomedical applications: a review. Acta Biomater 2012;8(1):20-30.

[39] Shih CC, Shih CM, Su YY, et al. Effect of surface oxide properties on corrosion resistance of 316L stainless steel for biomedical applications. Corrosion Science 2004;46(2):427-41.

[40] Simka W, Kaczmarek M, Baron-Wiechec A, et al. Electropolishing and passivation of NiTi shape memory alloy. Electrochimica Acta 2010;55(7):2437-41.

[41] Sims NA, Gooi JH. Bone remodeling: multiple cellular interactions required for coupling of bone formation and resorption. Semin Cell Dev Biol 2008;19(5):444-51.

[42] Stewart J, Rigg C, Trehan K. Critical human resource development: beyond orthodoxy. Financial Times / Prentice Hall 2007.

[43] Taddei EB, Henriques VAR, Silva CRM, et al. Production of new titanium alloy for orthopedic implants. Materials Science and Engineering: C 2004;24(5):683-7.

[44] Torabinejad M, Sabeti M, Goodacre C. Principles and practice of single implant and restoration-e-book. Elsevier Health Sciences 2013.

[45] Turkyilmaz I. Implant Dentistry: the most promising discipline of dentistry. BoD-Books on Demand 2011.

[46] Venkatsurya PKC, Girase B, Misra RDK, et al. The interplay between osteoblast functions and the degree of nanoscale roughness induced by grain boundary grooving of nanograined materials. Materials Science and Engineering: C 2012;32(1):330-40.

[47] Wennerberg A, Ide-Ektessabi A, Hatkamata S, et al. Titanium release from implants prepared with different surface roughness. Clin Oral Implants Res 2004;15(5):505-12.

[48] Wennerberg A, Albrektsson T, Jimbo R. Implant surfaces and their biological and clinical impact. Springer 2015.

[49] Xu R, Pang W, Yu Q, et al. Chemistry of zeolites and related porous materials: synthesis and structure. John Wiley \& Sons 2009.

[50] Yu X, Jiang Z, Wei D, et al. Tribological properties of magnetite precipitate from oxide scale in hot-rolled microalloyed steel. Wear 2013;302(1-2):1286-94. 